\title{
KORELASI KANDUNGAN FENOLIK DAN AKTIVITAS ANTIOKSIDAN DAUN JAMBU METE
}

\author{
Ika Trisharyanti Dian Kusumowati ${ }^{1}$, Rosita Melannisa ${ }^{1}$, Kartikaning Ratri ${ }^{1}$ \\ ${ }^{1}$ Fakultas Farmasi Universitas Muhammadiyah Surakarta \\ Correspondence to : Ika Trisharyanti Dian Kusumowati \\ Fakultas Farmasi Universitas Muhammadiyah Surakarta \\ email: Ika.Trisharyanti@ums.ac.id
}

\begin{abstract}
The ethanolic extract of Anacardium occidentale L. leaves contains phenolic compounds, flavonoids, alkaloids, saponins, tannins, and steroids that could have antioxidant activity. The aim of this research was to determine the correlation between the antioxidant activity and the phenolic compounds of the ethanol extract of Anacardium occidentale L. leaf. The DPPH methode was used to determine the antioxidant activity. The total phenolic determined using Folin-Ciocalteu reagent. There was a positive correlation between antioxidant activity and total phenolic content in the ethanolic extract of cashew leaf with correlation coefficient $R 2=0.5888$.
\end{abstract}

Keywords: Anacardium occidentale L., antioxidant, phenolic compounds

\section{PENDAHULUAN}

Radikal bebas yang berlebihan dapat mengakibatkan penyakit-penyakit degeneratif seperti diabetes, penyakit jantung dan kanker (Fajriah et al., 2007). Pada keadaan normal, tubuh manusia memiliki antioksidan yang cukup banyak (Achmad, 2004), untuk menghambat reaksi radikal bebas (Rohman dan Riyanto, 2005). Akan tetapi jika paparan oksidan tersebut berlebihan, antioksidan yang ada di dalam tubuh tidak mampu untuk mengatasinya (Hernani dan Rahardjo, 2006). Senyawa fenolik dan flavonoid yang terkandung dalam tanaman diketahui dapat menangkal radikal bebas. Salah satu tanaman yang mengandung fenolik dan flavonoid adalah jambu mete. Kandungan fenolik berperan penting dalam uji aktivitas antioksidan. semakin tinggi kandungan fenolik pada suatu sampel maka aktivitas antioksidannya juga semakin tinggi, yang ditunjukkan dengan harga IC50 yang lebih kecil (Nurwaini et al., 2006).

Ekstrak etanol daun jambu mete memiliki aktivitas antioksidan paling besar dibanding ekstrak air dan ekstrak petroleum eternya. Kandungan fenolik total yang dimiliki ekstrak etanol daun jambu mete juga lebih tinggi dibanding ekstrak lainnya (Jaiswal et al., 2010). sehingga perlu penelitian lebih lanjut untuk mengetahui aktivitas antioksidan ekstrak etanol daun jambu mete beserta fraksi-fraksinya. Tujuan dilakukan fraksinasi adalah untuk memisahkan senyawa-senyawa yang ada berdasarkan polaritasnya. Fraksi-fraksi yang diperoleh mungkin menunjukkan sifat kimia dan fisika senyawa yang lebih khas daripada ekstrak awalnya (Sarker et al., 2006).

Berdasarkan uraian tersebut maka menarik bila dilakukan penelitian untuk mengetahui hubungan antara aktivitas antioksidan ekstrak etanol daun jambu mete dan fraksi-fraksinya dengan kandungan fenolik totalnya.

\section{Metode}

1. Bahan dan Alat

a. Bahan

Ekstrak etanol daun jambu mete, heksan, etil asetat, methanol, kloroform, aquadest.

b. Alat

Rotary evaporator, laminar air flow, alat-alat gelas

2. Cara Kerja

a. Ekstraksi dan Fraksinasi Daun Anacardium occidentale L.

Pembuatan ekstrak etanol daun jambu mete dilakukan dengan metode maserasi. Simplisia daun jambu mete sebanyak 500 g dimasukkan ke dalam $3750 \mathrm{~mL}$ etanol dalam wadah stainless steel, ditutup rapat, dan didiamkan selama 5 hari terlindung dari cahaya. Hal ini bertujuan agar pelarut tidak menguap dan menghindari oksidasi 
dengan udara luar. Setelah 5 hari, dilakukan penyaringan dengan menggunakan corong Buchner. Maserat disimpan, lalu ampasnya diremaserasi dengan perlakuan sama. Maserat yang didapat dicampur kemudian diuapkan dengan menggunakan rotary evaporator dan waterbath sampai diperoleh ekstrak kental etanol daun jambu mete.

Setiap 10 gram ekstrak etanol diencerkan dengan $50 \mathrm{~mL}$ metanol: air (1:1), diaduk sampai semua ekstrak terlarut. larutan tersebut dimasukkan dalam corong pisah, difraksinasi menggunakan n-heksan, sehingga diperoleh fraksi n-heksan dan fraksi air. Fraksi n-heksan dipisahkan dan fraksi air difraksinasi dengan kloroform (1:1). Fraksi kloroform dipisahkan, fraksi air difraksinasi dengan etil asetat (1:1) sehingga diperoleh fraksi etil asetat dan fraksi air. Ekstrak etanol dan fraksi-fraksi yang didapat digunakan untuk uji aktivitas antioksidan.

b. Uji Aktivitas Antioksidan dengan Metode DPPH

Ekstrak diuji aktivitas penangkap radikal dengan Metode DPPH berdasarkan metode Zou et al (2004).

\section{Penentuan $\mathrm{IC}_{50}$}

Larutan stok sampel diambil dengan berbagai volume pengambilan, masing-masing larutan ditambahkan dengan 1,0 mL larutan DPPH dan etanol p.a sampai 2,5 mL. Campuran didiamkan selama 30 menit di tempat gelap. Seri konsentrasi yang dibuat kemudian dibaca serapannya pada panjang gelombang maksimal terhadap blangko etanol. Dilakukan juga pengukuran absorbansi kontrol (terdiri atas 1,0 mL DPPH dan 1,5 mL etanol p.a pada waktu tertentu). Percobaan uji aktivitas antioksidan direplikasi sebanyak tiga kali. Dihitung \% aktivitas antioksidan. $\mathrm{IC}_{50}$ dihitung dari persamaan regresi linear pada kurva kalibrasi antara konsentrasi terhadap \% aktivitas antioksidan. Harga $\mathrm{IC}_{50}$ merupakan konsentrasi ekstrak atau fraksi yang dibutuhkan untuk meredam 50\% DPPH.

\section{Penetapan Kadar Fenolik Total}

Kandungan fenolik total ditetapkan dengan metode Folin-Ciocalteu yang dilakukan oleh Lee et al., 2003 dengan beberapa modifikasi. Sejumlah sampel direaksikan dengan $50,0 \mu \mathrm{L}$ reagen FolinCiocalteu, ditambahkan aquabidest sampai 1,5 mL. Setelah dikocok dan didiamkan selama 5 menit kemudian ditambahkan $1,0 \mathrm{~mL} \mathrm{Na}_{2} \mathrm{CO}_{3} 7 \% \mathrm{~b} / \mathrm{v}$. Larutan divorteks selama 30 detik lalu didiamkan selama 30 menit dan dibaca absorbansinya pada $\lambda 729 \mathrm{~nm}$. Setiap ekstrak ditetapkan kadarnya sebanyak 3 kali replikasi. Kandungan fenolik total ditentukan sebagai ekuivalen asam galat (GAE)/ mg ekstrak.

\section{HASIL DAN PEMBAHASAN Aktivitas Antioksidan}

Uji aktivitas antioksidan dilakukan dengan metode DPPH (1,1-difenil-2-dipikrilhidrazil) menggunakan spektofotometer visibel. Metode ini didasarkan pada perubahan warna yang terjadi pada radikal bebas DPPH. Warna tersebut dapat berubah karena reaksi antara radikal bebas dengan satu atom hidrogen yang dilepaskan oleh senyawa yang terkandung dalam sampel untuk membentuk senyawa 1,1-difenil-2-dipikrilhidrazin yang berwarna kuning. Absorbansi yang diukur adalah absorbansi larutan DPPH sisa yang tidak bereaksi dengan senyawa antioksidan sampel. Absorbansi diukur setelah waktu inkubasi 30 menit (Zou et al., 2004) untuk memberikan kesempatan DPPH bereaksi dengan senyawa antioksidan sampel. Absorbansi diukur pada panjang gelombang maksimum yaitu 515,5 $\mathrm{nm}$.

Hasil pengukuran aktivitas antioksidan diperoleh harga $\mathrm{IC}_{50}$ dari yang terkecil adalah: fraksi etil asetat $(6,724 \pm 0,880 \mu \mathrm{g} / \mathrm{mL})$, ekstrak etanol $(9,667 \pm 0,261 \mu \mathrm{g} / \mathrm{mL})$, fraksi polar $(11,517$ $\pm 0,664 \mu \mathrm{g} / \mathrm{mL})$, fraksi kloroform $(19,872 \pm 2,092$ $\mu \mathrm{g} / \mathrm{mL})$, dan fraksi heksan $(34,422 \pm 3,394 \mu \mathrm{g} /$ $\mathrm{mL}$ ). Hasil percobaan menunjukkan bahwa ekstrak etanol daun jambu mete dan fraksi-fraksinya memiliki aktivitas antioksidan yang sangat kuat karena memiliki nilai $\mathrm{IC}_{50}<50 \mu \mathrm{g} / \mathrm{mL}$ (Zuhra et al., 2008). Apabila dibandingkan dengan vitamin $\mathrm{E}\left(\mathrm{IC}_{50}=7,093 \pm 1,372 \mu \mathrm{g} / \mathrm{mL}\right)$, fraksi etil asetat menunjukkan aktivitas antioksidan yang lebih baik.

Aktivitas antioksidan disebabkan karena adanya senyawa-senyawa fenolik. Menurut Nakiboglu et al. (2007) kemampuan penangkapan radikal bebas DPPH sangat dipengaruhi oleh gugus $\mathrm{OH}$ yang terdapat dalam senyawa fenolik. Perbedaan aktifitas antioksidan fenolik ditentukan oleh struktur kimia, jumlah dan posisi gugus 
hidroksi dan metil pada cincin. Semakin banyak gugus hidroksil yang tersubstitusi dalam molekul maka kemampuan penangkapan radikal bebasnya semakin kuat karena semakin banyak atom hidrogen yang dapat didonorkan (Yu Lin et al., 2009).

\section{Kadar Fenolik Total}

Kurva baku asam galat diperoleh dari menghitung regresi linier antara konsentrasi asam galat sebagai $\mathrm{X}$ dan absorbansi asam galat hasil reaksi dengan reagen folin sebagai Y. Diperoleh persamaan regresi $\mathrm{y}=0,083 \mathrm{x}+0,057$ dengan $\mathrm{R} 2=0,999$, persamaan tersebut yang digunakan dalam menentukan kadar fenolik total dari sampel. Hasil penetapan kadar fenolik total diperoleh hasil : fraksi etil asetat $(422,75 \pm 19,787 \mathrm{mg} / \mathrm{g})$, ekstrak etanol $(227,220 \pm 11,783 \mathrm{mg} / \mathrm{g})$, fraksi polar $(146,315 \pm 14,278 \mathrm{mg} / \mathrm{g})$, fraksi kloroform $(122,13 \pm 4,438 \mathrm{mg} / \mathrm{g})$, dan fraksi heksan $(65,582$ $\pm 6,484 \mathrm{mg} / \mathrm{g})$.

\section{Korelasi Aktivitas Antioksidan dan Kadar Fenolik}

Hasil regresi menunjukkan koefisien korelasi antara aktivitas antioksidan dan kadar fenolik ekstrak etanol daun jambu mete dan fraksi-fraksinya $=0,5888$. hal tersebut berarti $58,8 \%$ aktivitas antioksidan dari ekstrak etanol daun jambu mete dan fraksi-fraksinya disumbangkan oleh senyawa fenolik, sedangkan sisanya dipengaruhi oleh senyawa lain yang terkandung dalam ekstrak etanol dan fraksi-fraksi daun jambu mete seperti alkaloid, resin, saponin (Abulude et al., 2009), minyak atsiri (Jaiswal et al., 2010), asam anakrdat, kardol, senyawa flavonol seperti 3-O-galaktosida, 3-O-glukosida, 3-O-xylopiranosida, 3-O-arabinopiranosida, 3-arabinofuranosida, dan 3-O-ramnosida dari myricetin dan quercitin.

\section{SIMPULAN}

1. Hasil penelitian menunjukkan ekstrak etanol daun jambu mete dan fraksi-fraksinya memiliki aktivitas antioksidan.

2. Hubungan aktivitas antioksidan ekstrak etanol daun jambu mete dan fraksi-fraksinya dengan kadar fenoliknya menunjukkan korelasi positif sebesar $58,8 \%$.

\section{DAFTAR PUSTAKA}

Achmad, T.H. 2004. Biomolecular Mechanism of Antioxidant Activity on Aging Process: The New Paradigm in The Role and Life Care of Active Aging People, Procceding Simposium on Geriatri, Bandung.

Abulude, Ogunkoya, \& Adebote. 2009. Phytochemical And Antibacterial Investigation Of Crude Extracts Of Leaves And Stem Barks of Anacardium occidentale. Continental J. Biological Sciences 2. 12-16

Fajriah, S., Darmawan, A., Sundowo, A., \& Artanti, N. 2007. Isolasi Senyawa Antioksidan dari Ekstrak Etil Asetat Daun Benalu (Dendrophthoe pentandra L. Miq) yang Tumbuh pada Inang Lobi-Lobi. Jurnal Kimia Indonesia. 2 (1). 17-20.

Hernani, A. \& Rahardjo, M. 2006. Tanaman Berkhasiat Antioksidan, Penebar Swadaya. Depok.

Jaiswal, Y.S., Tatke, P.A., Gabhe, S.Y., \& Vaidya, A. 2010. Antioxidant Activity of Various Extracts of Leaves of Anacardium occidentale (Cashew). Research Journal of Pharmaceutical, Biological and Chemical Sciences. 1 (4). 112-119.

Lee, K.I., Kim, Y.J., Lee, H.J., \& Lee, C.H. 2003. Cocoa Has More Phenolic Phytochemical and Higher Antioxidant Capacity than Teas and Red Wine. $J$. Agric. Food Chem. 51. 7292-7295.

Nakiboglu, M. Urek, R.O. Kayali, H.A. \& Tarhan. 2007. Antioxidant Capacities Of Endemic Sideritis Sipylea And Origanum Sipyleum From Turkey. Food Chemistry. 104. 630-635.

Nurwaini, S., Sofiana, Y.R., Noor, I.R., \& Rahayu, V. 2006. Uji Aktivitas Antiradikal Ekstrak Herba Cakar Ayam (Selaginella doederleinii Hieron), Herba Keladi Tikus (Typhonium divaricatum (L) Decne) dan Daun Eugenia uniflora Linn Sebagai Sumber Alternatif Pencegahan Penyakit Degenatif, Laporan PKMP. 2 (18). 1-11.

Rohman, A. \& Riyanto, S. 2005. Daya Antioksidan Ekstrak Etanol Daun Kemuning (Murraya paniculata (I) Jack) Secara In Vitro. Majalah Farmasi Indonesia. 16 (3). $136-140$. 
Sarker, S.D., Latif, Z., \& Gray, A.I. 2006. Natural Products Isolation. Second Edition. Humana Press. Totowa New Jersey.

Yu Lin, H. Kuo, Y.H. Lin, Y.L. \& Chiang, W. 2009. Antioxidative Effect And Active Components From Leaves Of Lotus (Nelumbo nucifera). Journal Of Agricultural And Food Chemistry 57. 6623-6629.
Zou Y., Lu Y. \& Wei D. 2004. Antioxidant Activity Of Flavonoid Rich Extract Of Hypericum Perforatum L In Vitro. J Agric Food Chem. 52. 5032-9.

Zuhra, C.F., Juliarti, B.T., \& Herlince, S. 2008. Aktivitas Antioksidan Senyawa Flavonoid Dari Daun Katuk (Sauropus androgynus (L) Merr.). Jurnal Biologi Sumatra. Departemen Kimia FMIPAUSU. 3 (1). 


\section{PANDUAN PENULISAN NASKAH PUBLIKASI JURNAL BIOMEDIKA}

\section{Informasi Umum}

Jurnal Biomedika menerima makalah ilmiah dari para staf edukatif FK-UMS, para alumni FK UMS, dokter dari seluruh Indonesia dan luar negeri. Makalah dapat berupa peneletian, laporan kasus, kajian pustaka, resensi buku dan tulisan lain dalam bidang kedokteran dan kesehatan dan bebas dari unsur-unsur plagiarisme. Bahasa yang digunakan adalah bahasa indonesia yang baik dan benar berdasarkan Pedoman Umum Ejaan Bahasa Indonesia yang Disempurnakan dan Pedoman Umum Pembentukan Istilah, atau dalam Bahasa Inggris.

\section{Format Naskah}

Tulisan diketik pada kertas A4, batas atas, bawah , dan samping masing-masing $2,50 \mathrm{~cm}$, spasi doubel, font Times New Roman 11, tidak bolak-balik, maksimal 15 halaman dan 1 halaman abstrak.

Naskah penelitian (karangan asli) harus meliputi:

1. Judul, dibuat singkat bersifat informatif, dan mampu menerangkan isi tulisan, nama para penulis lengkap tanpa gelar beserta alamat kantor/instansi/tempat kerja lain, diletakkan di bawah judul, disertai alamat email untuk kepentingan korespondensi

2. Abstrak dalam bahasa Inggris dan Indonesia terdiri dari 100-150 kata, non aleniasi font Times New Roman 10, cetak miring, disertai keyword minimal 3 keyword

3. Pendahuluan, berisi latar belakang, rumusan, tujuan, serta manfaat penelitian (masing-masing tidak perlu dibuat sub judul sendiri)

4. Metode, jika ada pemisahan hanya ada dua yaitu alat \& bahan dan cara kerja, dibuat narasi

5. Hasil dan pembahasan digabung

6. Simpulan dan saran (jika ada)

7. Persantunan (ucapan terima kasih jika ada)

8. Daftar pustaka (metode Harvard jarak baris 1 spasi, antar referensi diberi jarak 2 spasi)

Naskah laporan kasus memuat latar belakang/alasan pelaporan kasus, maksud dan tujuan, manfaat, data klinis, ilustrasi serta diskusi, format naskah kajian pustaka, menyesuaikan, khususnya dalam pendahuluan hendaknya memuat penjelasan problematik yang dikaji, maksud, tujuan, dan manfaatnya serta pembahasan dari apa yang dikaji dan diakhiri dengan kesimpulan hasil kajian .

Tabel, grafik, dan gambar

Tabel/bagan/grafik/gambar/foto dibuat dengan jelas dan rapi, disertai keterangan yang jelas dan informatif. Diberi nomor menurut urutan dalam naskah, keterangan tabel ditulis di atas tabel, keterangan gambar ditulis di bawah gambar, font 10. Tabel tidak diperbolehkan ada garis vertikal, maksimal 3 baris horizontal penuh. Rujukan dalam teks dibuat berdasarkan model Harvard.

\section{Pengiriman Naskah}

Berkas tulisan hendaknya dikirim rangkap 2 disertai softfile dengan program Microsoft Word, dialamatkan kepada Redaksi Biomedika, Sekretariat Biomedika Fakultas Kedokteran Universitas Muhammadiyah Surakarta, Kampus 4. Jl. A. Yani Tromol Pos 1, Pabelan Surakarta Telp. (0271) 716844 Fax:(0271) 717670 Email: biomedika_ums@yahoo.com

\section{Proses Review}

Naskah setelah dilakukan seleksi redaksional akan dikirim kepada reviewer (mitra bestari) untuk dinilai dan hasil penilaian bisa berupa: 1) Diterima tanpa perubahan, 2) Diterima dengan perubahan, atau 3) Ditolak.

\section{Ketentuan lain}

Redaksi berhak memperbaiki susunan naskah atau bahasa tanpa mengubah isinya. Naskah yang telah dipublikasi tidak diperkenankan diterbitkan di jurnal ini.

Hormat kami,

Redaksi 
